\title{
Innovation and Reform of Financial Accounting under New Normal in China
}

\author{
Yang Li; Linghui Qu \\ Jilin University of Finance and Economics \\ 130017
}

\author{
Liwei Jing* \\ Jilin Scientific and Technical Information Institute \\ 130033
}

\begin{abstract}
The paper starts from the research method and the excepted purpose, and then describes the connotation of financial accounting. This part mainly introduces the historical evolution, functions and basic principles of financial accounting. Next, it puts forward financial accounting face many challenges now. This section discusses the impact of financial accounting from two parts of itself and the outside. Based on these crises, it analyses the response of financial accounting, namely innovation and change. Since then, it tells the development trend of financial accounting under New Normal in China, thus leads the emergency that the current financial accounting must innovate. This part will demonstrate it and do researches from different aspects and different points of view. The last part is the conclusion.
\end{abstract}

Keywords-financial accounting innovation; challenge and impact; New Normal

\section{INTRODUCTION}

As a kind of economic management activity, the main objective of financial accounting to comprehensively and systematically account and supervise the capital movement that has been realized. It also provides economic information to the external, the investors, creditors and the relevant government departments, such as corporate financial situation and profitability, etc. In the era of knowledge economy, science and technology that are constantly innovating are the key factors of economic growth. In the meantime, modern intangible capital gradually replace traditional physical capital to become the core of modern enterprise management. On the one hand, financial accounting is likely to expand its development space in the field of management because of its reform and innovation. On the other hand, financial accounting will also have more severe challenges because the reform and innovation. It should be paid more and more attention that how to innovate financial accounting better and serve the enterprise efficiently.

Under the economic globalization, traditional corporate financial accounting has been far from being able to adapt to the need of modern enterprise health and sustainable development. Therefore, modern corporate financial accounting innovation is imperative. Based on the importance and necessity of modern corporate financial accounting, the article analyses the challenges which modern corporate financial accounting face to, and then put forward some measures to reform and innovate the modern corporate financial accounting, so as to provide reference for practical operation and theoretical research of our country's corporate financial accounting.

\section{THE RELATIONSHIP BETWEEN FINANCIAL ACCOUNTING AND SOCIAL ENVIRONMENT}

Financial accounting is an important branch of accounting which is developed on the basis of traditional accounting. It is basically an accounting information system, which is based on the enterprise and faces market. Financial accounting focuses on the needs of enterprise information users, for example, shareholders, suppliers, banks, government agencies, business owners and other equity holders. It regards the enterprise as a whole, and uses the standardized GAAP rules as a guide. It also uses some procedures, such as confirmation, measurement, recording and reporting, etc. And at the meantime, it provides accounting information about the financial situation, operating results, cash flow and so on of the whole enterprise and its branches, which can help users make decisions.

Financial accounting takes the currency as the main measure. For enterprise transactions and events those have occurred, it uses the special method to identify and measure and takes the financial reports as the main form. It is a kind of external accounting that regularly provides accounting information to various economic stakeholders. Therefore, financial accounting is an important and fundamental work. By means of a serious accounting procedures, it provides useful information for decision making and actively participates in management decision, so as to improve the economic efficiency of enterprises and serve for the healthy and orderly development of the market economy.

As an artificial economic information system, financial accounting is inevitably influenced by the objective social environment. The impact of social environment on financial accounting is mainly realized by economic factors, political factors, legal factors, social culture factors, educational factors and technological factors.

Fund Project: This article is the stage results for the Ministry of education of humanities and social science research project "private financial docking SME financing gap of the financial system arrangements" (15YJC790050), Jilin Provincial Science and Technology Department 2016 soft science project "Jilin Province private capital docking" McMillan gap "The institutional arrangements and the realization of the path" (20160418026FG), Jilin Province Social Science 2017 general project "Jilin Province private capital effective docking" McMillan gap "law financial system design research" (2017B68) 


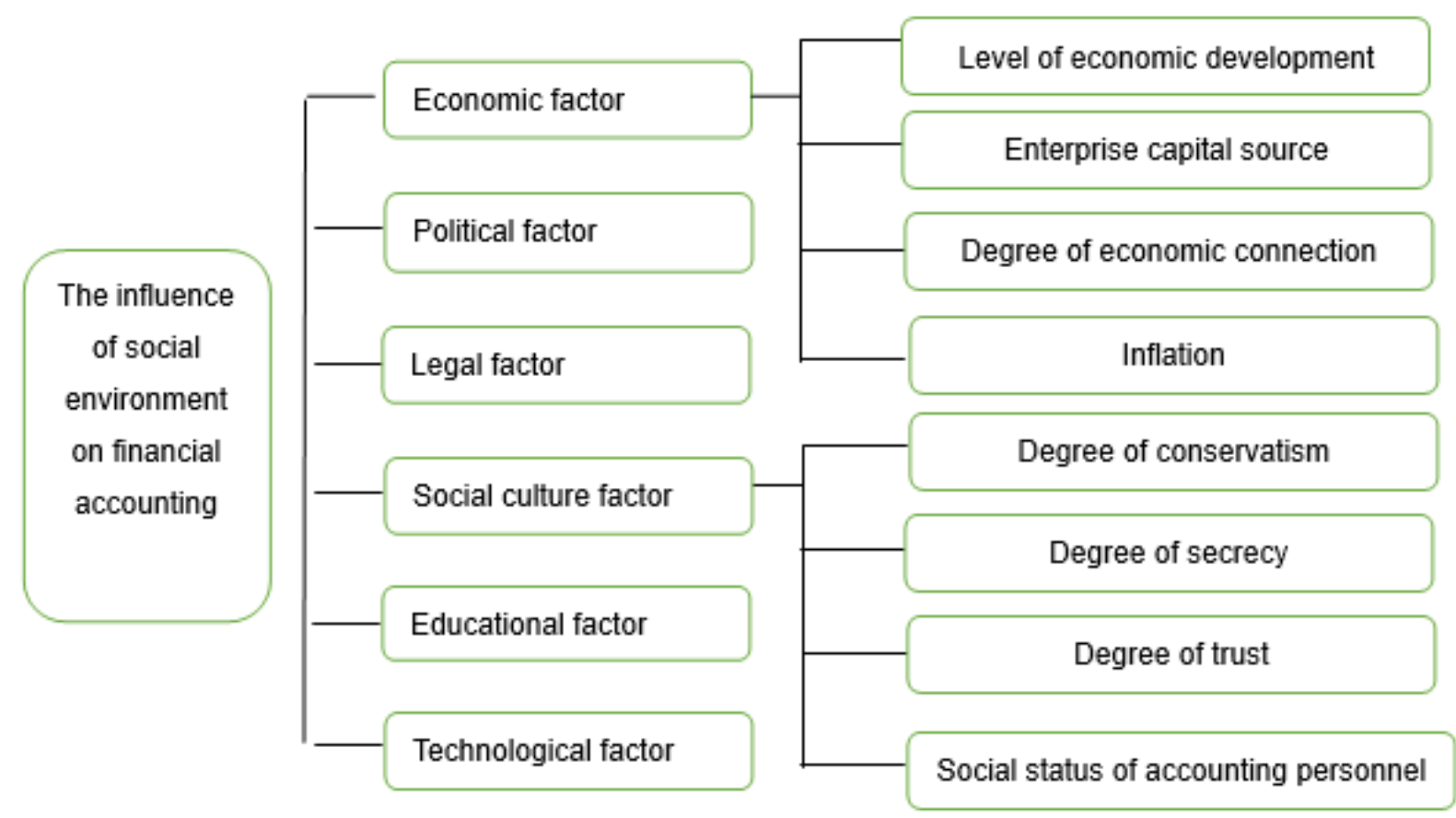

Fig. 1. The Influence of Social Environment on Financial Accounting

Among them, the economic factor is the most important and the most direct factor which affects and restricts the financial accounting. The way that the economic factor influence the financial accounting including the direct way and the indirect way. The indirect impact on financial accounting needs the help of politics factors, legal factors, social culture factors, educational factors, technological factors and other environmental factors. The direct impact of economic factors on financial accounting is achieved through the combined actions, for example, the level of social economic development, the enterprise capital source, the degree of economic connection with other countries and regions, the degree of inflation, etc [1].

Compared with economic factors, the influence of political factors on financial accounting is fluctuating. As countries all over the world have already considered economic development as the primary issue, the impact of political factors on financial accounting has shown a weakening trend. But political factors will still affect financial accounting indirectly through economic factors, legal factors and other factors.

Legal factors: at present, the countries all over the world mainly adopt the statutory law system and the case law system. In the countries with the statutory law system, its accounting principles and accounting practices are affected by the law are often extensive and profound, the representative of the statutory law system is the EU. On the contrary, in the countries with the case law system, the provisions of the laws for financial accounting are generally less and most of them are principles, the representative of the case law system is the United States.
Social culture factors refer to some factors in the social environment, such as the social customs, culture, fashion, moral values and other factors. The impact of social culture factors on financial accounting is often achieved in a subconscious way.

Educational factors include education structure, education orientation, education system, education level and so on. In general, the higher the level of education in a country or a region, the higher the level of financial accounting.

Technological factors: the impact of science and technology on financial accounting includes the impact of concept, the impact of accounting policy choices and the impact of accounting techniques [2].

It is worth noting that financial accounting is influenced and constrained by the social environment in which it is located, and financial accounting has a positive reaction to the social environment at the same time. This reaction is mainly manifested in the continuous development and improvement of the social environment. Financial accounting has many positive effects to the social environment. For instance, the process of applying science and technology to the theory and practice of financial accounting has enriched the technology itself, and put forward new requirements in the meantime. In addition, the true and fair information provided by financial accounting plays an active role in promoting the optimal allocation of social resources (including human resources), and promoting the fairness and efficiency of the market economy. What is more, even if financial accounting is bound by the laws, it will promote the continuous improvement of laws and regulations. 


\section{FINANCIAL ACCOUNTING UNDER NEW NORMAL IN CHINA}

\section{A. New Normal}

"New Normal" was originally put forward by the CIO of PIMCO Gross and Mohamed El-Erian, the former CEO of PIMCO and also the Chief Economic Adviser of Allianz Group, in May 2009. "New Normal" is mainly used to describe the global financial system structure has changed in the Post Crisis Financial Era. The state of prosperity which is formed by advancing the future assets and the spending power in the past has ended. In the new state, we will have new risks and new challenges.

China also put forward "New Normal" in May 2014, its connotation not only has the same side as the international "New Normal", such as reducing the rate of economic growth. Its connotation also has its own unique side, the state of economic development is different from the past, the economy is relatively stable, the form is more advanced, the division of labor is more complex and the structure is more reasonable. "The more the economy develops, the more important accounting is". As the controller of the healthy operation of social economy, accounting is the control tool to ensure the stable and orderly operation of economy [3].

\section{B. Challenges of New Normal to modern financial accounting}

It is well known that accounting is the product of economic development to a certain stage, the demands of different economic environment to accounting are also not the same. The development of innovation driving and brand competition under New Normal, not only pointing out the direction for the industrial structure adjustment and upgrading, but also affecting and changing the operation ideas and management mode of the enterprise economic activities. As an important part of enterprise micro-economic management activities, accounting should also correspondingly face the following challenges.

\section{1) The lack of theory support}

Asset is one of the most important concepts of financial accounting. At present, the concept of "economic resources" is in the dominant position, which believes that the nature of capital is a kind of economic resources. As a consequence, knowledge assets, brand equities, human capital can be considered as the assets of enterprises. However, due to the shackles of the traditional accounting theories and the limitations of people's recognition of accounting confirmation standards, these assets are not included into the accounting system, but are marginalized. On the one hand, the corporate admits these assets belong to the enterprise. On the other hand, these assets are not reflected in the accounting system, and even are rarely involved in the information disclosure, which is in the notes of financial accounting reports. The reason for this is manifest, the main reason is the lack of theoretical supports for the accounting recognition of such assets. Even though the scholars have studied the recognition of this kind of assets in the reality, so far there is no unified accounting recognition theories to support these assets, causing the accounting standardization process of such assets is hampered at some level [4].

\section{2) Unconventionality of accounting measurement}

The well-known economist Yuri Iriji said that the accounting measurement is the core function of accounting system. Robert S. Kaplan, the founder of Balanced Scorecard (BSC), also pointed out that no way to quantify or measure things, there is no way to conduct a very good management. Therefore, it can be seen that measurement occupies an important position in the accounting theories and accounting practices. Under New Normal, intangible assets such as intellectual assets, human capital, brand equities and so on play an dominant role in the value creation of enterprises, play an important role enhancing the core competitiveness of enterprises, and have a more important influence on the economic decisions of information users, thus it is particularly important to account or measure these kind of assets. Nevertheless, in the end how to measure or use what kind of index to measure these intangible assets, there is no uniform standards or guidance in the reality.

At present, it is only theoretically discussing the measurement methods of the various types of assets. For example, for intellectual assets, we use market evaluation method and network level assessment method, etc. For brand equities, in addition to the traditional financial assessment methods, including the cost method, the stock market value method, the income method and so on, also trying to build a number of other assessment models, such as Hirose model, CHirose model, Sinobrand evaluation method, etc. However, the application of these methods in practice is not smooth, and even some methods are obscure and arcane. Therefore, these methods have greatly hindered the measurement of such kind of assets in the accounting system [5].

\section{3) The limitations of financial reporting theory support}

Whether it is the Financial Accounting Standards Board (FASB), International Accounting Standards Board (IASB), or our country's accounting standards setting bodies are all currently with the view of "decision usefulness" as the leading goal of the financial reports. Under the traditional economic development model, the economic growth and the value creation mainly depend on tangible assets. As a consequence, the information provided by the financial reports is more reflect the value of tangible assets of the enterprise at a certain point in time and the change of value in a certain period.

Under New Normal, the economic growth mode has changed, so that intellectual assets, human capital, brand equities and other intangible assets all can create value. At the same time, the evaluation of economic growth is no longer the only GDP theory, but the Green GDP theory, which requires the enterprise's full consideration to all relevant stakeholders. Accordingly, the financial report provided by the enterprise should also be a comprehensive financial report based on the sustainable development theory and the stakeholder theory, which can meet the information needs of all stakeholders. However, the current financial reporting theories more supports to reflect the enterprise's business events which have been able to clearly measure, while less involved in 
knowledge, human resources, brand and other factors of production [6].

\section{Under New Normal, modern financial accounting how to do}

In the future, intangible assets are the fundamental to establish the sustainable competitive advantage. However, the existing financial accounting system of the enterprise, including the new financial rules, actually have ignored the important role of intangible assets. For some important intangible assets, such as intellectual assets, brand equities, human capital and so on, due to the influence of traditional accounting theory, measurement and reporting theory, it is difficult for these important intangible assets to be included in the financial reporting system to reflect and supervise. Therefore, the financial reports do not truly reflect the real value of the enterprise.

According to the accounting procedures, any financial reports must be generated on the basis of the accounting recognition, and with the accounting measurement as the core, the intangible assets are no exception. In other words, wanting to incorporate the intangible assets, such as intellectual assets, human capital, brand equities and other intangible assets into the financial reporting system, we should first make an innovative breakthrough research on the theory of current accounting recognition and measurement.

Although the International Financial Reporting Standards (IFRS) provides a set of experience and technology that can be used for reference, it is still necessary to combine the actual situation of our country, we should reasonably and effectively absorb the advanced achievements of accounting theory at home and abroad. We should be based on the principle of guidance, clear the nature of economy, balance the program in the fair and the results in the fair, recognize the development trend and practical feasibility of accounting recognition and measurement, and develop the original accounting theory to adapt to the economic development. In order to provide theoretical guidance for the establishment of such intangible assets standards at home and abroad, and also provide a number of useful information for China's economic transformation and upgrading [7].

\section{INNOVATION AND REFORM OF FINANCIAL ACCOUNTING}

\section{A. According to the actual need, to establish a sound financial accounting model}

In the era of knowledge economy, the proportion of intellectual work, the opposite of the manual labor, is increasing in the whole labor market. In the financial accounting work of enterprises, the intellectual work should be included into the accounting measurement, recording and identification. In the business capital statistics, the accounting personnel should not only pay attention to the financial capital of the enterprise, but also make the corresponding record to the knowledge capital of the enterprise. In the financial accounting of enterprises, the corporate should attach importance to the intellectual capital, and absorb the new financial accounting content. For example, the human resources accounting, which makes the enterprise financial accounting model can be more perfect and more sound, so as to provide enterprises with more comprehensive financial information.

\section{B. To further expand the financial accounting objectives}

With the development of social economy, the content of accounting is no longer just the financial situation, operating condition and cash flow of the enterprise. In order to fully satisfy the users' requirements, such as understanding the opportunities and risks faced by the enterprise, understanding the present situation and development prospect of the enterprise. The corporate should as far as possible widely disclose the non-financial information, including the background information of the enterprise, the forward-looking information, etc. With the arrival of knowledge economy, intellectual capital is essential to the survival and development of the enterprise. The financial reports should fully reveal and disclose the intellectual capital information, including intangible assets and human resources. In addition, at present, people's awareness of enterprises is experiencing the transformation from attaching great importance to the economy only to paying equal attention to both economy and society. Therefore, the content of accounting disclosure should also include implementation of social responsibility [8].

\section{To innovate financial reporting}

With the development of modern information technology and accounting computerization, the technical barriers of information collection, processing, handling and reporting has decreased, in the meantime, the cost has been reduced, and the enterprise can meet the different needs of information users. In space, the enterprise should provide the division reports. Through the decomposition of division information on the amount of total information and the deepening of division information on the quality, the enterprise can provide more relevant decision-making basis for information users to identify and analyze the opportunities and risks of enterprise different branches and subsidiaries. In time, financial accounting needs to provide the regular reports and the realtime reports.

According to the going-concern assumption and the time period assumption, traditional accounting reports are generally monthly and yearly. In the case of relatively stable economic life, information users can roughly predict the future of enterprises with the help of these accounting reports. But we will face an era in which the product cycle is continuously shortened, the competition is intense, the innovation is accelerating, and the uncertainty of economic activities is becoming more and more obvious, therefore the effective period of accounting information decision will be shortened greatly. As a consequence, it is necessary to establish a set of financial reporting system which can provide real-time information. On the one hand, regular reports will still emerge as a basis of making decisions. On the other hand, modern information and network technology make it possible to provide reports at any time. 


\section{To rich financial reporting delivery with the rational use of information technology(IT)}

Modern information technology, including database technology, computer network technology and remote communication technology, multimedia technology and CDROM storage technology and so on, lays the foundation for the financial reporting delivery. The financial reporting delivery which corresponds to the real-time performance of accounting reports will be networked and paperless. The enterprise can send the accounting information on the Internet, so that the degree of openness of information will be greatly improved and the information content will be also more diversified.

At the same time, it should be noted that the concentration of information is also the risk concentration. Because information is highly centralized and unified in the enterprises' internal information center platform, its security and confidentiality is essential. A number of vicious incidents will bring a deadly blow to the enterprise. For example, force majeure will cause damage to the server. What is worse, malicious innovation will leak out the corporate business secrets. Information technology is a double-edged sword, the stronger the dependence on it, the greater the damage after damaging. As a consequence, disaster prevention and information reserves must be designed and considered in advance and must continuously upgrade the technology level.

In addition, only the combination of information technology and advanced management methods of financial accounting can truly create value for the enterprise. The application of information technology, of course, is to strengthen management and service decision-making as the starting point. However, the enterprise application of information technology is bound to be limited and affected by the application environment. For instance, big companies want to customized the professional software, therefore, how to maintain a balance between promoting the application of the software and the distribution of the current power. For small businesses, the corporate resources are limited, and the financial resources are the same. Although the general software applications are more, after all, the business characteristics are very different and subject to the quality of financial accounting personnel. Therefore, information technology can be taken out of context, which can only play part of the function, so that its utility greatly reduced. There are also some companies, which subject to the commands of the companies or just follow the fashion, using the new system just for the new system, expanding costly labor force and material resources but the consumption is just the opposite to what they wish, and even the loss outweighs the gain. Therefore, the application of information technology must be combined with the independent needs of enterprise financial accounting, coordinated with management, and balancing the cost-effective principle of the application, so that to play the greatest role [9].

\section{E. To enhance the practicality of financial reporting}

In the new economic environment, the enterprise's customer demands are constantly changing, which requires corporate to constantly change financial reports of the enterprise to meet the needs of customers. In the current market information rapidly changing circumstances, the financial reports must adapt to the changes first, and keep up with the rhythm of the market, so that the enterprise's decision-making can provide timely and effective financial information.

Second, in addition to the summary and the statement of capital information, the financial reports of the enterprise should also include intellectual capital information and future information. With the speeding up of information dissemination in the economic era, the financial reports should put the timeliness in the first place. Because the traditional financial reports are limited by time and space, the financial reports in the economic era should be fully integrated with the real-time and periodicity, so that the diversified information combination can be realized.

\section{F. To use advanced accounting methods}

Monetary measurement reflects the traditional accounting measurement, but it is affected by a variety of factors, the stability of the unit value of monetary measurement is poor. The accounting information reflected by the less stable monetary measurement is easy to be distorted. In the economic era, the intangible assets have replaced the tangible assets as the core of the financial accounting measurement, and the intellectual resources measurement has replaced the financial resources measurement. Therefore, it is necessary to introduce the multiple measurement method into the accounting system, so that to achieve the diversified means of measurement.

At the same time, to update the accounting synchronously, namely intangible assets accounting. At present, in order to facilitate the management and accounting, the intangible assets of enterprises have generally been formally incorporated into the accounting system. The outsourcing intangible assets a qualitative intangible assets, including patents, copyrights, franchise rights, land use rights and so on are all belong to the recognized intangible assets in the traditional accounting. While the self-created intangible assets are excluded from the assets, the self-created intangible assets are also not reflected in the book, which can not correctly measure the value of enterprises. Therefore, the investors also can not really understand the composition of intangible assets and the investment in scientific research.

At present, human resources and intellectual capital should be added to measure together in intangible assets. In the "intangible assets", the "human resources", "intellectual assets" and other classification items will be added, and independent accounting these items respectively. It is obvious that when the intangible assets are increased, the owner's equity is increased at the same time [10]. 


\section{G. To improve the overall quality of financial accounting personnel}

Under the condition of economic globalization, the financial accounting personnel of enterprises not only need to accurately record the economic activities of enterprises, but also to manage the economic conditions of enterprises. Therefore, the financial accounting personnel need to improve their management ability and professional quality.

First and foremost, it is necessary for the financial accounting personnel of modern enterprises to have certain innovation consciousness and ability. Diligent studying, more thinking and truly and accurately reflecting the costs and value of enterprises, in the meantime, understanding how to ensure the enterprise obtain more economic benefits when achieving the effective allocation of resources.

Second, the financial accounting personnel of modern enterprises should have a composite knowledge structure. Based on a higher level of scientific culture and accounting management, to set up the global perspective and Scientific Development Concept. Based on the globalization of world knowledge economy, to set up the correct knowledge values so that making the accounting work internationalization [11].

\section{CONCLUSION}

In any enterprises, financial accounting occupies a very important position. To a certain extent, financial accounting information determines the important decisions of an enterprise manager in some matters. At the same time, financial accounting plays a very important role in the production of enterprises and the healthy development of enterprise economic operation. The success of creative financial accounting has a direct impact on the production the operation of the enterprise and other work. We need to seriously study and take appropriate measures to constantly establish and improve a perfect financial accounting model.

In a word, in the process of economic globalization, with the rapid changes in market information, a variety of adverse conditions faced by the enterprise in the process of production and operation are gradually increasing. Therefore, in order to adapt to these changes, it is necessary for the enterprise accounting work to reform and innovate. At this stage, the rapid development of the socialist market economy has led to the development and expansion of China's enterprises, but it also exposes more new problems in the production and operation of the enterprise, so that the enterprise financial accounting deepening the reform is imminent. How to deal with the corporate financial accounting issues, we need to be based on Scientific Development Concept, with the power of the rapid development of information technology, to promote the innovation and the development of enterprise financial accounting. Finally, pushing the enterprise financial accounting system into a new era.

\section{REFERENCES}

[1] Hun Xiaohong. Some Problems In The Reform of Financial Accounting [J]. China's New Technology and New Products. 2013(09).

[2] Qi Haiyan. Some Problems In The Reform of Financial Accounting [J]. China's New Technology and New Products. 2013(02).

[3] Li Xin. Some Problems In The Reform of Financial Accounting [J]. China's New Technology and New Products. 2013(19).

[4] Sun Junhua, Xu Huimin, Wang Wei. On Social Environment's Impact on Financial Accountancy [D]. Xingtai, Hebei. Xingtai University. 2015.

[5] Shao Shuning. The Impact of Information Technology on Enterprise Accounting [J]. Chinese \& Foreign Entrepreneurs. 2013(5).

[6] Fang Qing, Jin Chenggong. The Analysis of the Impact and Requirement of Economic Globalization on the Process of Accounting Internationalization in China [J]. Shangqing. 2012(48).

[7] Zhang Jixian. The Reform and Innovation of Financial Accounting [J]. The Forestry Science and Technology In formation. 2014.

[8] Gao Jie, Hou Wei, Zhu Haiqiang. Analysis on the Way of Financial Accounting Innovation and Strengthening [J]. The Chinese Market. 2013.

[9] Lin Kangcong. Analyses How to Innovate and Strengthen Financial Accounting $[\mathrm{J}]$. China High Technology Enterprises. 2013.

[10] Yu Fengzhu. The Corresponding Transformation of Knowledge Economy and Financial Accounting [J]. Journal of Shijiazhuang Institute Railway Technology. 2013.

[11] Tang Xiangxi, Li Jinglu, Zhou Jiangyan. The Value Theory of Enterprise Intellectual Assets [M]. Beijing: Intellectual Property Publishing House Co.,Ltd. 2014 